\title{
Effects of Gonadotropin Releasing Hormone analogue in Enhancements of Pregnancy in repeat Breeding Dairy Cows in and around Mekelle, Tigray, Ethiopia
}

\author{
Birhanu Hailu, ", Berihu Gebrekidan², Solmon Raju², Alemselam Birhanu², Gebrhiwot Tadesse ${ }^{2}$ \\ ${ }^{1}$ Samara University, College of Veterinary Medicine, P.O.Box.132, Samara, Ethiopia \\ ${ }^{2}$ Mekelle University, College of Veterinary Medicine, Mekelle, Ethiopia
}

Email address:

birhailu2002@gmail.com (B. Hailu)

\section{To cite this article:}

Birhanu Hailu, Berihu Gebrekidan, Solmon Raju, Alemselam Birhanu, Gebrhiwot Tadesse. Effects of Gonadotropin Releasing Hormone Analogue in Enhancements of Pregnancy in Repeat Breeding Dairy Cows in and around Mekelle, Tigray, Ethiopia. Animal and Veterinary Sciences. Vol. 3, No. 1, 2015, pp. 12-17. doi: 10.11648/j.avs.20150301.13

\begin{abstract}
Clinical trial was carried out to evaluating the effects of GNRH analogue (buserelin acetate) along with AI in repeat breeding cross breed cows on enhancement of pregnancy. The trial was also aimed at evaluation of dose variation on conception rate. Sixty six cross breed dairy cattle which were apparently healthy, exhibits estrus regularly were selected and assigned randomly in to three equal groups( $\mathrm{A}, \mathrm{B}$ and $\mathrm{C})$; two treated groups and one control group. Group $\mathrm{A}(\mathrm{n}=22)$ cattle were injected intramuscularly a $20 \mu \mathrm{g}$ buserelin acetateat along with AI and Group B (n=22) cattle have injected with dose of $10 \mu \mathrm{g}$ Buserelin acetate. Group C $(\mathrm{n}=22)$ cattle were receive no treatment and considered as a control group, given a single service. These cows were examined for pregnancy after three months through rectal palpation. Additional history was taken from herd owners. The pregnancy rates recorded were $68 \%, 59 \%$ and $32 \%$ in the cattle grouped with A, B and C respectively. The conception rates of the treated groups exceeds control group by $36 \%$ and $27 \%$ respectively. Treated groups showed a significant statistical variation $(\mathrm{P}<0.05)$ as compared to control group. Dose variation between two treated groups has an effect on pregnancy rate with significant variation. Other observed finding was that treated first and second parity cows became more responsive to therapy than those with more than two parity with a significant variation $(\mathrm{P}<0.05)$. The study revealed that the use of GNRH analogue therapy at the time of AI can enhance pregnancy rate. This would be helpful and cost effective to minimize financial losses incurred from milk production loss, managmental and feed cost. This might be achieved through reducing calving interval and treating repeat breeding cases. The benefit cost ratio indicates that individual cow could benefit small holder farmer by 140 USD within a single month.
\end{abstract}

Keywords: Crossbred Cattle, Estrus, Repeat Breeding GNRH Analogue, Pregnancy Rates

\section{Introduction}

Livestock production is one segments of agriculture constituting means of improving living standards of exponentially increasing poor farmers in many regions of developing world (Sere and Steinfeld, 1995; FAO, 2009). Eight-five percent of the Ethiopian people are heavily dependent on the contribution of agriculture with particular emphasis of livestock for multipurpose activity (Tegegn, 1998). Cattle production has been considered as major economic sector and still to be continued in the future in Ethiopia (FAO, 2009). The country has high potential of cattle population (Tegegnet al., 1999). These production sectors can significantly reduce poverty and ensure food security. To get expected productions, improvement in management,environment, genetical, health and reproductive management is mandatory (Azage et al., 1981).

For bringing of changes or upgrading reproductive performance, understanding of reproductive traits is necessary in bovine species (Hoglund, 2013). These traits are; age at first service, number of services per conception, day's open and calving interval and these are bases for profitable dairy cattle and beef cattle production system (Azage et al., 1981 and Stvenson et al., 2000). Otherwise, low reproduction efficiency hinders genetic improvement as local breeds which were not crossed leads to low milk production, long calving 
interval, late sexual maturity, short lactation length and hence such factors directly affects the livelihoods of farmers and gross domestic product of the nation (Mukosa-Mugerwa et al., 1993).

For the development of livestock industry, particularly the dairy farm, it must be highly integrated with the great biotechnological advancements to improve reproduction and genetics of farm animals (Foote, 2002). Artificial insemination technology was come into practices for years ago (Foote, 2002 and Bale, 2003). AI was introduced to our country, some years ago, by the ministry of agriculture and had got wide acceptance by the society with a hope to upgrading the local breeds (Yemane et al., 1993). But only knowledge of semen deposition in the reproductive tracts will not result in high conception rate and high milk yield since factors such as female fertility and heat detection accuracy must be considered in conjunction with the AI.

Using this technology, many exotic breeds were crossed with local one with improved potential of milk yield by many folds having good mangemetal situations (Foote, 2002). However, this technology is not without constraints. In contrast to the above condition, major problem observed now days is low conception rate using AI. This was the main problem that needs a solution to increase pregnancy rate in crossbred cattle (Morrel, 2011). According to the available literatures, major reproductive problems identified were, delayed ovulation, anovulation, anestrus, cystic ovaries and early embryonic death which cause cows to show repeated estrus cycle and low conception rate (Maureral, 1985). Such conditions were observed due to hormonal deficiency; GNRH produced by hypothalamus which controls synthesis and release of luteinizing hormone (LH) and follicle stimulating hormone (FSH). These two hormones have combined effects on follicular development, ovulation and corpus lutetium functions (Douglas, 1998).

Many protocols were taken in to consideration to treat reproductive problems associated with such hormonal imbalances (Mwaagna, 2004). One of these techniques were the use of synthetic GNRH analogue that has been used to modify reproductive efficiency of normal as well as repeat breeder dairy cows which has been investigated extensively. Synthetic buserelin acetate has an added advantage of improved half life in the blood circulation, greater stability to enzymatic degradation, increased receptor affinity, prolonged biological potency and less antigenic than the other molecules for repeated use(Cline,2002 and Ehler et al.,2013). Exogenous administration of these hormones at different period of estrus of cow may lead to treat disease condition or cysts in the ovary or may rectify the hormonal insufficiency to these cows (Morgan, et al., 1993; Bearden and Fuquay, 1997). The GNRH had been used as treatment for fertilization rates, embryonic mortality and as a therapeutic treatment for cystic ovaries (Gustafsson et al., 1986).

In case of Ethiopia and Tigray region in particular, limited knowledge was available about the use of synthetic hormones for treatment of hormonal imbalances and for enhancement of pregnancy rates. No work was done to investigate the effects of GNRH analogue on enhancement of conception rate of cross breed repeat breeders of dairy cattle and therefore the present study was conducted with the aim of enhancing the fertility rates in cross breed cattle with specific objectives of: observing the effects of GNRH analogue (buserellin acetate) on enhancement of pregnancy on treated groups as compared to control and to evaluate the effects of dose variation between treated groups. Finally the study estimates financial benefits obtained from treatment of hormones.

\section{Materials and Methods}

\subsection{Description of the Study Areas}

The study was conducted in Tigray regional state;located in northern part of Ethiopia and bordering with Eritrea in the north, Sudan in the west, Afar in the east and Amhara in the southwest. The region extends from $120^{\circ} 13^{\prime}$ to $140^{\circ} 54^{\prime} \mathrm{N}$ and from $36^{\circ} 27^{\prime}$ to $40^{\circ} 18^{\prime} \mathrm{E}$. It has seven Administrative Zones and this study was carried out in the capital city of the region which is located at $783 \mathrm{~km}$ north of Addis and geographically located $39^{\circ} 29^{\prime} \mathrm{E}$ and $13^{\circ} 3^{\prime} \mathrm{N}$ longitude. Mekelle is surrounded by south east zone in south and east, Eastern zone from north, central zone from west. It has an average temperature of $20^{\circ} \mathrm{c}$ and experiences an average annual rain fall of $600 \mathrm{~mm}$. Livelihoods of the people in and around the city depends on trade, civil servants and agricultural practices. Dairy farming is one of the major farming systems practiced in the city. Small holder farmers around the city supply moderate amount of milk to urban dwellers and some of the farmers in the nearby area practice a mixed crop livestock production system. The area is moderately covered with savanna, bushy and low weed vegetations. Both small holder farmers and commercial dairy farms owners were included the study.

\subsection{Study Population and Husbandry System}

The study was conducted in repeat breeding cross breed dairy herds owned by small holder farmers and commercial dairy farms. These cows were kept in stall facility; fed grass hay, concentrate composed of wheat by products, crop residues, forages and other locally prepared fermented alcohol by products 'atella'. These dairy herds were milked twice per day and vaccinated regularly against common infectious diseases. In general, dairy cows were managed in similar agro ecological and climatic conditions. Artificial insemination was practiced based on the visual observation of standing heat and mucosal discharges by herd attendants.

\subsection{Study Design and Selection of Animals}

A randomized clinical trial was conducted to study effects of buserelin acetate on enhancement of pregnancy rates and evaluating the effects of doses variation on pregnancy. The study period was ranged from January to April 2010 in and around Mekelle. A total of 66 dairy cows were selected from thirty seven farms for this study. Cows with normal cycling, 
no clinical abnormalities, failed to conceive after two successive inseminations, not previously assigned for any study and aged from three to ten years were included in the study. Cows that were treated at first AI and back to estrus couldn't be reassigned for the study. The study repeat breeding cross breed dairy cows were selected based on these factors and equally divided in to three groups each consisting of twenty two dairy cows. These animals were randomly assigned into three protocols.

\subsection{Study Procedures}

The study had three main phases. Phase one: training of thirty seven herd owners or their representatives for having more experience about the symptom and behavioral changes of estrus cycle. Farmers were made aware about mucosal discharges from vulva, restlessness, frequent urination; stand to be mounted and raised tails during estrus exhibition. As soon as such symptoms were observed, they informed to make phones to local inseminator immediately and included in the study. Phase two: based on the above criterion; selection process of animals for the study was carried out and assigned randomly to control and treatment groups. The first group A ( $\mathrm{n}=22)$ was inseminated along with intramuscular injection of $20 \mu \mathrm{g}(5 \mathrm{ml})$ buserelin acetate. Second group $\mathrm{B}(\mathrm{n}=22)$ was also inseminated along with injection of $10 \mu \mathrm{g}$ $(2.5 \mathrm{ml})$ of $\mathrm{GNRH}$ analogue. Third group $\mathrm{C}(\mathrm{n}=22)$ was assigned as a control group, receive no treatments except single AI. Phase three: After cows were followed for 90 days post AI, pregnancy diagnosis was carried out using a rectal palpation in cows' herds with history of failure to return to estrus. The cows were considered as pregnant if we were able to palpate the fetal membrane, amniotic vesicles, cotyledons and fetus otherwise the cows were classified as negative.

\subsection{Estimation of Financial Losses and Benefits Obtained after Treatment}

Financial losses of single cows per cycle were computing and estimated by considering the following variables. Average enhanced conception rate as result of the treatment, average milk yield per head of cross breed cow, duration of cycle and current market price of one liter of milk. During this financial losses calculation, costs of calf loss, management and feed costs were not considered.

\subsection{Data Collections and Statistical Analysis}

Study variables were collected from dairy herd owners by asking breed type, insemination and service history, parity, management condition, milk yield, price of milk per liter, time and day of estrus exhibition and previous condition of dairy herds. During this study period, pregnancy diagnosis was made through rectal palpation and positive and negative results were recorded. Some data were collected from farm records about animals' previous milk yield, clinical cases, origin of the animal, replacement herd and breeding type. The experimental study was of a randomized type in which data was collected from treated and controlled study animals. Collected data was fed to Microsoft Excel spread sheet and process of data cleaning, handling, validating and coding was done on this spread sheet. The difference in pregnancy proportion, age and parity between treated groups against control one was compared using descriptive statistics and Pearson's chi-square tests (SPSS16.0; 2005). The significance level of differences was observed at $\mathrm{P}$ value of less than $5 \%$.

\section{Results}

Out of the 66 dairy cows included in the study, 35 cows were found to be pregnant. A total of 15 cows from group A were recorded as pregnant with the conception rate of $68 \%$. In group B, from the 22,13 of them were conceived with the conception rate of $59 \%$ and the remaining 7 were from the control group as indicated in Table-1. Those animals treated with the higher dose of buserelin acetate exceeds in conception rate to second group by $9 \%$. In general, treated groups recorded higher pregnancy rate in comparison with controlled group with average score of $32 \%$ over controlled one and the rest results obtained from each group was indicated in Table-1.

Conception rate of group A (treated) exceeds conception rate of group $\mathrm{C}$ (control) by $36 \%$ with significant statistical variation $\left(\chi^{2}=4.79, \mathrm{P}=0.029\right)$. The recorded conception rates of group B was $59 \%$ greater than group C by $27 \%$ with significant statistical variation $\left(\chi^{2}=7.108, \quad \mathrm{P}=0.008\right)$. Comparison between treated groups, Group (A) with higher dose of buserellin acetate scores more conception rate with significant difference as compared to group B which receive half dose of group A. Comparison among the three groups; conception rate in both treated groups were significantly higher than control groups. Overall comparison of treated and controlled group was shown in table-2. Management condition, season and parity variation doesn't show any significant variation in treated groups as compared to controlled group, dairy herds of younger age were found more response to therapy as compared to older treated cows with a statistical significance variation $\left(\chi^{2}=3.93, \mathrm{P}<0.05\right)$ (Table-2).

Table 1. Results of the various protocols with their respective percentages.

\begin{tabular}{|c|c|c|c|}
\hline Group & No. animals in each protocol & Type of Protocol & Pregnancy rate \\
\hline A & 22 & $20 \mu \mathrm{g}(5 \mathrm{ml})$ buserelin acetate along AI & $15 / 22(68 \%)$ \\
\hline B & 22 & $10 \mu \mathrm{g}(2.5 \mathrm{ml})$ buserelin acetate along AI & $13 / 22(59 \%)$ \\
\hline $\mathrm{C}$ & 22 & Controlled group(receive no treatment) & $7 / 22(32 \%)$ \\
\hline
\end{tabular}


Table 2. Cross tabulation of the treated groups with the controlled animals.

\begin{tabular}{|c|c|c|c|c|c|c|}
\hline \multirow{2}{*}{\multicolumn{2}{|c|}{ Cross tabulated groups }} & & \multicolumn{3}{|l|}{ Group C } & \multirow{2}{*}{ Significance Level } \\
\hline & & & Negative & Positive & Total & \\
\hline \multirow{4}{*}{$\mathrm{A}^{*} \mathrm{C}$} & \multirow{4}{*}{ Group A } & Negative & 7 & 0 & 7 & \multirow[t]{4}{*}{$\left(\chi^{2}=4.79, \mathrm{P}=0.029\right)$} \\
\hline & & Positive & 8 & 7 & 15 & \\
\hline & & Total & 15 & 7 & 22 & \\
\hline & & & Group C & & & \\
\hline \multirow{4}{*}{$\mathrm{B}^{*} \mathrm{C}$} & \multirow{4}{*}{ Group B } & Negative & 9 & 0 & 9 & \multirow[t]{4}{*}{$\left(\chi^{2}=7.108, P=0.008\right)$} \\
\hline & & Positive & 6 & 7 & 13 & \\
\hline & & Total & 15 & 7 & 22 & \\
\hline & & & Group B & & & \\
\hline \multirow{3}{*}{$\mathrm{A} * \mathrm{~B}$} & \multirow{3}{*}{ Group A } & Negative & 7 & 0 & 7 & \multirow[t]{3}{*}{$\left(\chi^{2}=14.830, \mathrm{P}=0.000\right)$} \\
\hline & & Positive & 2 & 13 & 15 & \\
\hline & & Total & 9 & 13 & 22 & \\
\hline
\end{tabular}

\section{Discussion}

Repeat breeding have been a problem dairy farmers, causing economic damage and the present study was carried out to evaluate the effects of buserelin acetate on repeat breeding cross breed cows in association with improvement of pregnancy rate. The study demonstrated that supplementation of buserelin acetate along with $\mathrm{AI}$ increase pregnancy rate by $63 \%$ as compared to control group. Treatment improves pregnancy rate significantly in the first two groups $(\mathrm{P}<0.05)$ and comparison between treated groups, the first group with higher dose was observed with conception rate of $68 \%$, exceeds the second group with significant statistical variation $(\mathrm{p}<0.05)$. This shares similar results with experiments done by Anjum et al., 2010. Improvement in conception rate was also associated with increment of doses of GNRH analogue. This finding was in line with reports by Kharche and Srivastava (2007). This improvement in pregnancy rate may be related to timing of ovulation or synchronization ovulation with insemination and increased progesterone secretion by corpus luteum due to increased LH surge by treatment with GNRH analogue (Karg et al, 1980; Mc Dougall et al., 1995).

The present study showed an improvement in conception rate of $36 \%$ which is approximately the same to the works of Kharche and Srivastava (2007) that's around 39\% using the same analogue and same dose. So, this study supported dose dependent effect of GNRH analogue, done on repeat breeder cross breed cows under different environmental condition and breeding season. This result confirmed the ideas that GNRH analogue can increase conception rate at the time of AI despite the fact that breed type, management, environmental and physiological status of the animals which might be contributing factors towards the differential fertility response to GNRH analogue treatments (Thatcher et al., 1993, Ullah et al., 1996 and Cam et al., 2002). Several works reported that there was an increase in conception rates using GNRH analogue in repeat breeder cows than the control ones (Stevenson et al., 1990). Study by Blowey (1999) also indicated that an improvement of $7 \%$ over the controlled groups in the GNRH treated repeated breeder dairy cows. In contrast to the present study, Drew and Peter (1994) stated that administration GNRH analogue $10 \mu \mathrm{g}$ GNRH did not improve fertility at the time of AI.

From the treated 16 first and second parity repeat breeding cows, 13 of them $(81 \%)$ were found to be pregnant and this difference has a statistical significant variation. Most of animals treated with this protocol show a response indicating that dairy herds need administration of hormones to boost reproduction. This result is in agreement with study by Gustafsson (1986). The overall pregnancy rates were higher in treated than the controlled groups. These results indicates that there is high incidence of reproductive organ disturbances such as ovarian cysts, delayed ovulation, anovulation, anestrous or defective corpus luteum function which could be improved by administration of GNRH analogue. This may also be caused by lack of good management and malnutrition in the study area.

Intramuscular injection of GNRH analogue enhances pregnancy rate that prevents owners from economic losses as a result of prolonged calving interval since cows return to heat repeatedly. This protocol is fair in cost and has fewer tendencies for pharmacological intervention in reproductive tract of the cow as compared to other complicated and expensive protocols. Financial losses of cows per cycle were computing and estimated based on the following parameters. (Average conception rate $=31 \%$, Average milk yield $=14$ liters per head, treated cows get conceived over control $=21$ cows, average number of days per cycle $=21$ days). So, the total financial loss would be computed as: 14 liters of milk per day* 21 days per cycle $* 21$ cows $* 10$ birr $=61,740$ Birr or \$3118) at which owners going to loss in addition to loss of calf, management and feed costs. From this we can understand that as the cow takes more time, the loss will be more severe. A farmer could loss birr $2940 / \$ 148.48$ per cycle from single cow; that highly affects its livelihood. In calculation of benefit cost ratios, it is indicated that farmers would be benefitted if bought GNRH analogue (buserelin acetate) for treatments of repeat breeding dairy cows rather than living with problem. The cost is effective and affordable to farmers to pay 25 to 50 birr (2.20-4.40 \$) to the $10 / 20 \mu \mathrm{g}$ of the hormone rather than losing 140 USD. 


\section{Conclusion and Recommendation}

The finding of our study revealed that the use of GNRH analogue (buserelin acetate) therapy along with AI improved in pregnancy rate in repeat breeding cross breed cows. The scored conception rates were $68 \%$ and $59 \%$ in the first and the second treated groups respectively as compared to the control groups $(32 \%)$. This improvement in conception rate indicated that farmers would be benefitted financially as benefit exceeds in the benefit-cost ratios. So, individual house hold was benefitted worth of $\$ 140$ as compared to those control one. Based on these results the following points are recommended.

- The GNRH analogue administration along with AI improved reproductive performance of repeat breeding dairy cows

- Farmers should be aware on beneficial effects of the gonadotropin releasing hormone analogues (buserelin acetate)

- Incensement of dose of buserelin acetate may enhance more conception rates among the repeat breeding dairy cows

- GNRH analogue can be effectively used to overcome the problem of repeat breeding in crossbred cattle dairy cows and farmers could prevent financial losses by using buserelin acetate as an alternative treatment of choice

\section{Acknowledgements}

The authors acknowledge to the Ethiopia Ministry of Science and Technology for financial support and to Mekelle University for provision of necessary facilities and administrative work which had remarkable role for the success of research work.

\section{Conflicts of Interest Statements}

None of the authors has any financial or personal relationships that could inappropriately influence the contents of the paper.

\section{References}

[1] Anjum, I. A., Usmani, R. H., Tunio, M. T. and Abro, S. H.(2010). Improvement of Conception rate in Cross Breed Cattle by Using Gonadotropin Releasing Hormone (GNRH) analogue thereapy. Agricultura Tropica et Subtropica, 43:1

[2] Azage, T., Galal, E. and Beyene, K. (1981).A Study on the reproduction of local zebu andF1cross breeds (European Zebu) Cows, Number of services per conception, gestation length and days open till conception. Ethiopian. J. Agri. Sci 3:1-14.

[3] Azage, T. and Alemu, G. (1998). Prospect for Urban, Periurban dairy development in Ethiopia. Ethiopian Society of Animal production (ESAP), publication no5 Addis Ababa Ethiopia.
[4] Bale, O. (2003). Artificial Insemination Practice in Nigeria, Nigerian Journal of Animal Production.

[5] Banerjee, G. (1998). A Text Book of Animal Husbandry, $8^{\text {th }}$ edition, Oxford and IBH publishing corporation New Delhi

[6] Bearden, J. and Fuquay, W. (1992). Applied Animal Reproduction, $3^{\text {rd }}$ edition Mississippi State University

[7] Beckers, F., Szenci, O., Takacs, E., Sulon, J. and Sousa, N. (2006). Evaluation of GNRH treatment 12 days post A.I in the reproductive performance of dairy cows. Theriogenology.

[8] Blowey, W. (1999). The repeat breeder cow, $3^{\text {rd }}$ edition, A Veterinary Book for Dairy Farmers.

[9] Cam, M. A. - Kuran, M. Yildiz, S. Selcuk, E. 2002. Fetal growth and reproductive performance in ewes administered GNRH agonist on day 12 post-mating. Anim. Reprod. Sci., vol. 72, p. 73-82.

[10] Cline, A. M., (2002). Efficiency of Synthetic Gonadotropin Releasing Hormone analogue for the control of ovulation during estrus synchronization protocols, Animal Science, Physiology of Reproduction.

[11] Connor, O. (2000). Dairy Integrated Reproductive Management, Pennsy State University.

[12] Dougall, S., Williamson, N. and Macmillan, K. (1995). GNRH induces ovulation of dominant follicle in primiparous dairy cows undergoing anovulatory follicle turn over. Anim. Reprod. Sci. 39: 205-214.

[13] Drew, S. and Peters, A. (1994). Veterinary Pharmacology and Therapeutics, Endocrine pharmacology. Vet Rec .134-267.

[14] Ehlers, K., Halvorson, L. and Glob. liber (2013).Gonadotropin Releasing Hormone and Gonadotropin Releasing Hormone Receptors. ISSN, 1756-2228.

[15] FAO. (2000). Food and Agricultural Organization, year book, Rome Italy.

[16] FAO., 2009. Food and Agricultural organization of the United Nations, The State of Food and Agriculture. Livestock, food security and poverty reduction.pp32-50.

[17] Foote, R. (2002). The history of Artificial Insemination, Selected notes and notables, American society of Dairy Sciences

[18] Goley R and Kadu M. (1995). Efficacy of PGF2 $\alpha$, GNRH and HCG in treatment of repeat breeder cow. Indian Veterinary Journal 72: 472-475.

[19] Gustafsson, H,. Larsso, H, Kindah .and A.Madei. (1986). Sequential Endocrine Changes and Behavior during estrus and met estrus in repeat breeder and virgin heifer's Anim Repro Sci 10:261.

[20] Hoglund, K. J., (2013), Gene mapping of Reproductive Traits in Cattle, Faculty of Veterinary Medicine and Animal Science, Department of Animal Breeding and Genetics, Uppsala, Sweden

[21] Karg, H., Claus, R., Gunzler, O., Rattenberger, E., Pirchner, F. (1980). Hormonal Recognition of cyclicity and infertility in cows under practical conditions. In proceeding of the $11^{\text {th }}$ World congress.Disease of cattle Israel, Pp.885-894. 
[22] Karten, M. and River, J. (1986).Endocr Rev.7:4466.Protective effects of analogs of luteinizing hormonereleasing hormone against chemotherapy-induced testicular damage in rats

[23] Kharche, S. and Srivastava, S. (2007). Dose dependent effect of GNRH analogue on pregnancy rate of repeat breeder cross breed cows. Indian Veterinary Research institute Anim.Repro. Sci. India.

[24] Markandeya, N. (2006). Approaches to enhance conception rate and embryo survivability, Department of Gynecology and Obstetrics Veterinary College, Reproductive Techniques to augment Fertility in dairy animals. Karnataka Veterinary Animal and Fisheries Sciences University.

[25] Mauurer, R. and Echternkamp S. (1985). Repeat breeder Females in Beef cattle Influences and causes, J.Anim Sci, 61:624.

[26] Michael, O, Jeffrey, Stevenson, Brenda, M. and Garth, R. (1993). Administration of GNRH at estrus influences pregnancy rates Serum concentration of LH, FSH estradiol-17 beta, pregnancy specific protein and progesterone, proportion of the luteal cell types and invitro production progesterone in dairy cows. J Anim Sci 71:185-198.

[27] Morgan, W. Lean, I. (1993). Gonadotropin Releasing Hormone treatment in cattle a Meta analysis of effects on conception at the time of insemination. Aust Vet J 70: 205-9.

[28] Morrel, M., (2011). Artificial Insemination; Current and the Future Trends: Swedish University of Agricultural Science, Uppsala, Sweden

[29] MukasaMugaerwa, E., Agaze, T., Tafese, M and Teklu, Y. (1993). Reproductive Efficiency of Bosindicus (Zebu) cows under Artificial Insemination. Anim. Reprod Sci 24: 63-67.

[30] Mwanga, S. E., Zdunczyk, S., and Janowsk, T., (2004). Comparative Efficacy of Hormonal and Non-Hormonal Treatment Methods in Ovarian Afunctions affected dairy cows

[31] Nagaraja, R. Devaraj, M. (2006). Multi facet Roles of GNRH in Reproduction. Veterinary college, Karnataka Veterinary, animal and Fisheries Sciences University.

[32] Petrie, A. and Watson, P. (2000): Statistics for Veterinary, Revised edition. Blackwel Science Ltd., Osney Mead Oxford OX2 OEL, 25 John Street, London WCIN2 BS.
[33] Schels, H. Mostafawi, D., Morgan, W. (1978). The effect of GNRH on pregnancy rate of artificially inseminated cows.Vet Rec; 103: 31-32.

[34] Sere, C. and Steinfeld, H., 1995.World livestock production system, Current status, Issues and Trends pp6-12.

[35] Stevensen, J, Thompson, W. Forbes, G. Lamb, D. Gerieger, L, Corah. (2000). Synchronizing estrus and ovulation in beef cows after combination of GNRH, norgestment and prostaglandin with or without timed ovulation .J Anim sci, 78:1747-1758.

[36] Stevenson J .Caller, Scoby.and .Phatak. (1990).Double insemination and gonadotropin releasing hormone treatment of repeat breeding dairy cattle J. Dairy Sci 73:1766.

[37] Stojilkovic, S and Catt, K. (1995). Rec. Prog. Horm. Res 50: 161-205.

[38] Srivastava, S.K. and Kharche, S. D. (2002). Effect of GNRH on fertility in crossbred cows. Indian. J. Anim. Sci. 72:428430 .

[39] Tegegn, T., Alemayehu, A. and Ayele, G. (1999). Cross border livestock trade in Southern and south eastern Ethiopia border lines. OSSREA (organization for social science research in eastern and southern Africa) Development Research report series, Commercial printing enterprises.

[40] Thatcher, W. W., M. Drost, J. D. Savio, K. L. Macmillan, K. L. Entwistle, E. J.-P. Schmitt, R. L. de la Sota, and G. R. Morris.1993. New clinical uses for GNRH and its analogues in cattle. Anim. Reprod. Sci. 33:27-49.

[41] Ullah, G., J. W. Fuquay, T. Keawkhong, B. L. Clark, D. E. Pogue, and E. J. Murphey. 1996. Effect gonadotrophinreleasing hormone at estrus on subsequent luteal function and fertility in lactating Holsteins during heat stress. J. Dairy Sci. 79: $1950-1953$.

[42] Vishwanath R. (2003). Theriogenology, 59:585-598.

[43] Yemane,B.,Chernet,T.,Shiferaw,T.(1993). Improved Cattle breeding, National Artificial Insemination Center, and Addis Abeba, Ethiopia. 